\title{
The role of eating frequency on total energy intake and diet quality in a low-income, racially diverse sample of schoolchildren
}

\author{
E Whitney Evans ${ }^{1, *}$, Paul F Jacques ${ }^{2,3}$, Gerard E Dallal ${ }^{2,3}$, Jennifer Sacheck ${ }^{2}$ and \\ Aviva Must ${ }^{2,4}$ \\ 'Weight Control and Diabetes Research Center, Brown University School of Medicine, 196 Richmond Street, \\ Providence, RI 02903, USA: ${ }^{2}$ Friedman School of Nutrition Science and Policy, Tufts University, Boston, MA, USA: \\ ${ }^{3}$ Jean Mayer-USDA Human Nutrition Research Center on Aging, Tufts University, Boston, MA, USA: ${ }^{4}$ School of \\ Medicine, Tufts University, Boston, MA, USA
}

Submitted 21 June 2013: Final revision received 20 January 2014: Accepted 4 February 2014: First published online 29 April 2014

\begin{abstract}
Objective: The relationship of meal and snacking patterns with overall dietary intake and relative weight in children is unclear. The current study was done to examine how eating, snack and meal frequencies relate to total energy intake and diet quality.

Design: The cross-sectional associations of eating, meal and snack frequencies with total energy intake and diet quality, measured by the Healthy Eating Index 2005 (HEI-2005), were examined in separate multivariable mixed models. Differences were examined between elementary school-age participants (9-11 years) and adolescents (12-15 years).

Setting: Two non-consecutive $24 \mathrm{~h}$ diet recalls were collected from children attending four schools in the greater Boston area, MA, USA.

Subjects: One hundred and seventy-six schoolchildren, aged 9-15 years.

Results: Overall, $82 \%$ of participants consumed three daily meals. Eating, meal and snack frequencies were statistically significantly and positively associated with total energy intake. Each additional reported meal and snack was associated with an $18.5 \%$ and a $9.4 \%$ increase in total energy intake, respectively $(P<0 \cdot 001)$. The relationships of eating, meal and snack frequencies with diet quality differed by age category. In elementary school-age participants, total eating occasions and snacks increased HEI-2005 score. In adolescents, each additional meal increased HEI-2005 score by 5.40 points $(P=0.01)$, whereas each additional snack decreased HEI-2005 score by 2.73 points $(P=0 \cdot 006)$.

Conclusions: Findings suggest that snacking increases energy intake in schoolchildren. Snacking is associated with better diet quality in elementary school-age children and lower diet quality in adolescents. Further research is needed to elucidate the role of snacking in excess weight gain in children and adolescents.
\end{abstract}

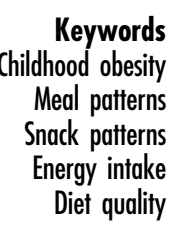

Since the 1970s, childhood obesity prevalence has increased in developed countries worldwide ${ }^{(1)}$. Estimates suggest that up to $60 \%$ of obese adolescents become obese adults $^{(2)}$ and that dietary patterns established during childhood and adolescence often persist into adulthood ${ }^{(3)}$. Accordingly, there has been an increased focus on diet and dietary behaviours in children and adolescents. Consumption of sugar-sweetened beverages ${ }^{(4-8)}$, increased portion sizes $^{(9,10)}$ and eating more meals away from home ${ }^{(5,11)}$ have all been positively associated with excess weight gain in childhood. Further, nationally representative US trend data from children aged 2 to 18 years show that average eating frequency has increased from three to five daily eating occasions between 1970 and the 2000s ${ }^{(12)}$ and average total daily energy intake has increased by $770 \mathrm{~kJ}$ (184 kcal) over the same time frame ${ }^{(13)}$. These findings, among others, have led researchers to explore what role eating frequency plays in dietary intake and weight status in childhood.

The observed increase in eating frequency is largely attributable to snacking, given that the average American child eats three snacks per day ${ }^{(14)}$. Snacking contributes nearly one-third of total energy consumed, the majority of which comes from desserts and sugar-sweetened beverages ${ }^{(14)}$. Further, compared with breakfast, lunch and dinner meals, snacks have a significantly higher energy density ${ }^{(15)}$. Despite these findings, the cross-sectional literature on the 
relationship between eating frequency and snacking generally suggests an inverse relationship with weight status $^{(16,17)}$.

Given the inconsistencies in the literature, no consensus exists with regard to the impact of eating frequency on relative weight in children ${ }^{(18,19)}$. A 2013 review of this relationship cited inconsistent definitions for snacking occasions, methodological limitations in cross-sectional studies and a shortage of prospective studies, and concluded that the evidence base is lacking ${ }^{(17)}$. In the absence of clear guidance to parents, schools and clinicians as to an ideal eating frequency to help reduce childhood obesity risk, the objective of the present study was to explore the relationships of eating frequency, meal frequency and snack frequency with total energy intake and diet quality in an effort to clarify the possible role of eating frequency in excess weight gain in children. Further, given that younger children appear to have a better ability to self-regulate intake ${ }^{(20)}$, and that adolescents typically have greater autonomy over their eating habits, have greater spending power and consume more meals outside the home ${ }^{(21)}$, a secondary objective was to examine whether these associations differ between elementary school-age (9-11-year-olds) and adolescent participants (12-15-year-olds). We hypothesized that eating frequency would be positively associated with total energy intake and inversely associated with diet quality in this racially diverse, low-income sample of school-age children.

\section{Methods}

\section{Participant information}

The present analysis was done using dietary data collected from a sample of participants enrolled in the Daily D Study, a randomized trial designed to determine the appropriate level of vitamin D supplementation needed to prevent serum vitamin D inadequacy in school-age children (5th through 8th graders). The trial included 312 students who attended one of five schools in three communities in the greater Boston, Massachusetts area; ran from October 2011 to December 2012; and consisted of four study visits: baseline, 3 months, 6 months and 1 year. Other than providing a vitamin D supplement to all participants, the Daily D trial protocol did not include any dietary intervention. At the 3-month study visit, 183 participants were recruited from four of the schools into an adjunct study: the diet sub-study. Recruitment did not occur at the fifth school due to logistical constraints. Students were ineligible for the Daily D trial if they were currently taking vitamin $\mathrm{D}$, multivitamin supplements or oral glucocorticoids; or had rickets, cystic fibrosis, kidney disease, sarcoidosis, irritable bowel syndrome, epilepsy or HIV/AIDS. Participation in the diet sub-study required complete weight and height measurements at baseline and willingness to complete two $24 \mathrm{~h}$ diet recalls. Parental informed consent and child assent was obtained for both the Daily D Study and the diet sub-study. Both protocols were approved by the Tufts University Institutional Review Board.

\section{Dietary assessment}

Research supports that school-age children are capable of providing reliable $24 \mathrm{~h}$ diet recalls with valid energy estimates without the assistance of a parent or guar$\operatorname{dian}^{(22,23)}$. Therefore, trained registered dietitians collected two, non-consecutive weekday, $24 \mathrm{~h}$ diet recalls directly from participants using the University of Minnesota Nutrition Data System for Research (NDSR) software (versions 2011; Nutrition Coordinating Center, Minneapolis, MN, USA) ${ }^{(24)}$. The first $24 \mathrm{~h}$ diet recall was collected in person at the time of the 3-month study visit and the second $24 \mathrm{~h}$ diet recall was collected 3-21 d later over the telephone, as research suggests that mode of administration does not affect accuracy in children ${ }^{(25)}$. NDSR employs a multiple-pass method and a standardized portion-size manual to decrease measurement error. Participants were taught how to use the portion-size manual at the time of the in-person recall and were provided with a copy for use during the telephone recall. All $24 \mathrm{~h}$ diet recalls were collected on Tuesday through Saturday to reflect usual weekday intake. Recalls were collected only for days when school was in session. This was done to avoid any variation introduced by differences in eating patterns between weekday and weekend day recalls ${ }^{(26)}$.

\section{Eating frequency}

Within the NDSR protocol, participants identify the name and time of each reported eating occasion. The names for each eating occasion are chosen from a predefined list that includes: breakfast, lunch, dinner/supper, school lunch, snack and other. For the present analysis, an eating occasion was defined as any distinct time when a participant reported consuming at least one food or beverage item, excluding water, regardless if the occasion was designated a meal (breakfast, lunch, dinner/supper or school lunch) or a snack. No participants designated an eating occasion as 'other'. Therefore, to examine possible differences in energy intake by eating occasion type, meals were defined as breakfast, lunch, dinner/supper or school lunch. Snacks were defined as a separate category. Previous publications on eating frequency have considered eating occasions to be independent if they are separated by a minimum of $15 \min ^{(12,27)}$. Of the 1574 occasions reported by this sample, only nine occasions (0.05\%) were consumed within 15 min of each other and were combined. Thus, our definition of eating frequency is consistent with previous research and also reflects the integrity of how elementary school-age children selfdefine eating occasions. Eating frequency estimates were determined separately for each $24 \mathrm{~h}$ recall. To examine how dietary intake patterns vary by reported eating frequency, we grouped participants into groups using 
reported weekday eating frequency from the in-person $24 \mathrm{~h}$ recall. Participants were considered 'infrequent eaters' if they reported one to three daily eating occasions, 'average eaters' if they reported having four daily eating occasions, and 'frequent eaters' if they reported five or more daily eating occasions.

\section{Total energy intake}

Total energy intake estimates were determined for each $24 \mathrm{~h}$ diet recall using NDSR.

\section{Diet quality}

Diet quality was measured using the Healthy Eating Index 2005 (HEI-2005), which is a scoring system developed by the US Department of Agriculture, Center for Nutrition Policy and Promotion to measure degree of compliance with the 2005 Dietary Guidelines for Americans ${ }^{(28)}$. The HEI-2005 is made up of twelve nutrient- and food-based component scores. Nine of the components (fruit, whole fruit, total vegetables, dark green and orange vegetables, total grains, whole grains, milk, meat and beans, and oils) represent adequacy components, whereas the saturated fat, sodium and energy from solid fat, alcohol and added sugars (SoFAAS) represent moderation components.

The standards used to assign maximum HEI-2005 scores for each component are based on overall population needs. Given that children require a more nutrient-dense diet to achieve recommended intakes without exceeding energy needs, the HEI-2005 standards have been modified ${ }^{(29)}$. Mean estimated energy requirements published by the Institute of Medicine were used as the basis for this modification. Estimated energy requirements are quite different for male and female adolescents, such that adolescents have been stratified for the purpose of the present analysis. Specifically, for children aged 9-11 years, female adolescents aged 12-18 years and male adolescents aged 12-18 years, the HEI-2005 standards were modified according to the $7531 \mathrm{~kJ}$ (1800 kcal), $8368 \mathrm{~kJ}$ (2000 kcal) and $10042 \mathrm{~kJ}$ (2400 kcal) MyPyramid eating patterns, respectively ${ }^{(28-30)}$. Total and component HEI-2005 scores were calculated for each $24 \mathrm{~h}$ diet recall using the methodology developed for use with NDSR as well as the detailed technical report of the US Department of Agriculture, Center for Nutrition Policy and Promotion ${ }^{(31,32)}$.

\section{Covariates}

Demographic data collected on the vitamin D supplementation trial consent forms included age, sex and race/ ethnicity. At the baseline visit, parents completed an additional questionnaire which provided information on maternal education and eligibility for free or reduced-price school lunch. Physical activity was assessed by self-report at the baseline visit via the Block Kids Physical Activity Screener (NutritionQuest, Berkley, CA, USA). The screener asks about the frequency and duration of leisure activities, school activities, chores and part-time employment, and has been validated using an objective measure of physical activity $^{(33)}$. Its analysis provides relative estimates of total minutes of daily activity as well as minutes spent in low, moderate and vigorous activity daily. These estimates along with methodology provided in the 2008 Physical Activity Guidelines for Americans were used to categorize participants as 'sedentary' if their reported weekly moderate activity totalled less than $150 \mathrm{~min}$, 'moderately active' if it totalled 150-300 min and 'active' if it exceeded $300 \mathrm{~min}^{(34)}$. Each minute of vigorous activity was deemed equivalent to 2 min of moderate activity.

\section{Statistical analyses}

All statistical analyses were conducted using the statistical software package SAS version 9.2, at the two-sided 0.05 level of significance. Using data from the in-person $24 \mathrm{~h}$ recall, participants were initially grouped into eating frequency categories and dietary characteristics were compared. Tukey's Honestly Significant Difference test was used to adjust for multiple comparisons. To determine whether specific dietary characteristics (eating frequency, meal frequency and snack frequency) were related to total energy intake and diet quality, measured by the total HEI-2005 score, separate multivariate mixed models were estimated using the MIXED procedure. Participants provided up to two $24 \mathrm{~h}$ recalls and, thus, they had up to two estimates for eating frequency, meal frequency and snack frequency as well as total energy intake and diet quality. Accordingly, a mixed model allowed us to account for having repeat measures for each dietary variable. We tested for the presence of effect modification by age group (elementary school-age (9-11 years) $v$. adolescents (12-15 years)) by evaluating the statistical significance of an interaction term in each model. Given shared food environments within each school, we controlled for school in each of our models a priori. Finally, we assessed the need to control for age at baseline, sex, race/ethnicity, maternal education, free or reduced-price school lunch eligibility and physical activity. Variables were retained in the model if their inclusion induced a change in the point estimate greater than $10 \%{ }^{(35)}$.

\section{Results}

A total of 176 participants provided a reliable, in-person $24 \mathrm{~h}$ diet recall and 168 participants provided a reliable, second $24 \mathrm{~h}$ diet recall. Twenty-five participants provided both $24 \mathrm{~h}$ diet recalls in person, given difficulty in reaching them by telephone. Despite this difference in collection methodology, there were no statistically significant differences in reported eating frequency between the two recalls with $(t=0.51 ; P=0.61)$ and without $(t=0.37 ; P=0.71)$ these twenty-five participants. Accordingly, all 176 participants who provided at least one reliable in-person recall were included in the current analyses. Participants were 9-15 
years old, with a mean age of 11.4 years, $40.0 \%$ were white and $64.2 \%$ were sedentary (Table 1 ). Forty-six per cent were overweight or obese and $63.8 \%$ were eligible for free or reduced-price school lunch.

In total, $82 \%$ of participants reported consuming three meals per day in their in-person $24 \mathrm{~h}$ diet recall. With

Table 1 Characteristics of elementary school-age children (9-11 years) and adolescents (12-15 years) who participated in the Daily D diet sub-study, greater Boston area, MA, USA, October 2011 to December 2012

\begin{tabular}{lc}
\hline & $\begin{array}{c}\text { Analytic sample } \\
(n 176)^{*}\end{array}$ \\
\hline Sex (\% female) & $50 \cdot 6$ \\
Age (years) & \\
Mean & $11 \cdot 4$ \\
SD & $1 \cdot 5$ \\
Race/ethnicity $\left.{ }^{*} \%\right)$ & \\
White & $40 \cdot 0$ \\
Black & $12 \cdot 6$ \\
Hispanic & $13 \cdot 7$ \\
Asian & $13 \cdot 1$ \\
Other & $20 \cdot 6$ \\
Weight status (\% overweight/obese) & $46 \cdot 0$ \\
Maternal education (\%) & \\
$\quad$ No college education & $50 \cdot 0$ \\
Some college, college and/or & $50 \cdot 0$ \\
$\quad$ graduate education & \\
Qualify for free or reduced-price & $63 \cdot 8$ \\
school lunch (\% yes) & \\
Reported physical activity† (\%) & \\
Active (>300 min/week) & $14 \cdot 2$ \\
Moderately active (150 to & $21 \cdot 6$ \\
$\quad$ < 300 min/week) & \\
Sedentary (<150 min/week) & $64 \cdot 2$ \\
\hline
\end{tabular}

*Sample sizes vary slightly due to missing data.

†Minutes of moderate and vigorous physical activity measured using the Block Kids Physical Activity Screener. Categories are based on the 2008 Physical Activity Guidelines for Americans ${ }^{(34)}$. respect to meal location, $77 \%$ of participants consumed breakfast at home, $95 \%$ of children consumed lunch at school and $91 \%$ of participants reported consuming dinner at home (data not shown). Participants were grouped into eating frequency categories using data from the inperson $24 \mathrm{~h}$ diet recall to compare dietary intake patterns between groups (Table 2). Both 'average eaters' and 'frequent eaters' consumed three meals per day, on average. Finally, 'infrequent eaters' consumed 2.0 fewer snacks and 2908 fewer kJ/d (nearly $700 \mathrm{kcal} / \mathrm{d}$ ), on average, as compared with 'frequent eaters' who consumed $2 \cdot 5$ snacks and $8443.9 \mathrm{~kJ} / \mathrm{d}(2016.8 \mathrm{kcal} / \mathrm{d} ; P<0.05)$. There were no statistically significant differences in reported mean energy, protein or fat intake between 'infrequent eaters' and 'average eaters'.

There was no statistically significant effect modification by age category in the association of eating frequency with total energy intake, so results are presented on the unstratified sample (Table 3). For all participants, each additional reported eating occasion was statistically significantly associated with $11.6 \%$ greater total energy intake in a multivariable mixed model adjusted for free or reduced-price lunch eligibility $(P<0 \cdot 001)$. In similar but separately estimated models, each additional reported daily meal was associated with $18.5 \%$ greater total energy intake $(P<0.001)$, and each additional reported daily snack was associated with $9.4 \%$ greater total energy intake $(P<0.001)$.

Table 4 shows the relationship between eating frequency and diet quality in this sample. HEI-2005 total score ranged from 21.9 to $82 \cdot 3$ points out of a possible 100 . Because associations differed between elementary schoolage and adolescent participants, all multivariable mixed

Table 2 Dietary characteristics of the first in-person $24 \mathrm{~h}$ diet recall provided by elementary school-age children (9-11 years) and adolescents (12-15 years) who participated in the Daily D diet sub-study*, greater Boston area, MA, USA, October 2011 to December 2012

\begin{tabular}{|c|c|c|c|c|c|c|}
\hline & \multicolumn{6}{|c|}{ Reported eating frequency } \\
\hline & \multirow{2}{*}{\multicolumn{2}{|c|}{$\begin{array}{c}\begin{array}{c}\text { 'Infrequent eaters' } \\
(n \text { 32) }\end{array} \\
1-3 \text { occasions/d }\end{array}$}} & \multirow{2}{*}{\multicolumn{2}{|c|}{$\begin{array}{c}\begin{array}{c}\text { 'Average eaters' } \\
(n 59)\end{array} \\
4 \text { occasions/d }\end{array}$}} & \multirow{2}{*}{\multicolumn{2}{|c|}{$\begin{array}{c}\begin{array}{c}\text { 'Frequent eaters' } \\
(n 85)\end{array} \\
5+\text { occasions/d }\end{array}$}} \\
\hline & & & & & & \\
\hline & Mean & SD & Mean & SD & Mean & SD \\
\hline Meal frequency $\ddagger$ & $2 \cdot 34^{a}$ & 0.65 & $2.97^{\mathrm{b}}$ & 0.41 & $2.98^{b}$ & 0.41 \\
\hline Snack frequency§ & $0.5^{\mathrm{a}}$ & 0.62 & $1.0^{\mathrm{b}}$ & 0.41 & $2 \cdot 5^{\mathrm{c}}$ & 0.88 \\
\hline Diet quality\|l & $49 \cdot 2^{a}$ & 10.9 & $56 \cdot 4^{\mathrm{b}}$ & 11.5 & $55 \cdot 5^{\mathrm{a}, \mathrm{b}}$ & $13 \cdot 0$ \\
\hline Energy intake (kJ) & $5535 \cdot 8^{a}$ & $2492 \cdot 0$ & $6575 \cdot 4^{a}$ & $1821 \cdot 7$ & $8443 \cdot 9^{\mathrm{b}}$ & $2457 \cdot 2$ \\
\hline Carbohydrate intake (g) & $166 \cdot 8^{a}$ & $75 \cdot 1$ & $209 \cdot 0^{\mathrm{b}}$ & 68.4 & $274 \cdot 8^{\mathrm{C}}$ & 87.4 \\
\hline Protein intake $(\mathrm{g})$ & $58 \cdot 2^{\mathrm{a}}$ & $29 \cdot 6$ & $63 \cdot 8^{\mathrm{a}}$ & $17 \cdot 2$ & $79 \cdot 4^{\mathrm{b}}$ & $27 \cdot 3$ \\
\hline Fat intake $(\mathrm{g})$ & $47.9^{a}$ & 29.8 & $55 \cdot 4^{\mathrm{a}}$ & 21.7 & $69 \cdot 4^{\mathrm{b}}$ & 27.4 \\
\hline Average energy $(\mathrm{kJ})$ per meal & $2073 \cdot 7^{\mathrm{a}}$ & 966.7 & $1941 \cdot 4^{a}$ & 516.6 & $1964 \cdot 0^{\mathrm{a}}$ & $585 \cdot 3$ \\
\hline Average energy $(\mathrm{kJ})$ per snack & $1257 \cdot 7^{a}$ & $916 \cdot 9$ & $890 \cdot 1^{a}$ & 576.9 & $1055^{a}$ & 731.0 \\
\hline
\end{tabular}

a,b,c Mean values within a row with unlike superscript letters were significantly different $(P<0.05)$ according to Tukey's Honestly Significant Difference test. *Participants were grouped into eating frequency categories using data from the first, in-person $24 \mathrm{~h}$ recall.

†Eating frequency: number of reported daily eating occasions.

¥Meal frequency: number of reported daily meals (breakfast, lunch, dinner/supper).

$\S$ Snack frequency: number of reported daily snacks.

IIAs measured by the HEI-2005 (Healthy Eating Index 2005) total score. 
Table 3 Associations of daily eating, snack and meal frequencies with total energy intake in elementary school-age children (9-11 years) and adolescents (12-15 years) who participated in the Daily D diet sub-study*, greater Boston area, MA, USA, October 2011 to December 2012

\begin{tabular}{|c|c|c|c|c|}
\hline & \multicolumn{4}{|c|}{ Energy intake } \\
\hline & \multicolumn{2}{|l|}{ Total† } & \multicolumn{2}{|l|}{ Percentage $†$} \\
\hline & Multivariate effect estimate & $P$ value & Multivariate effect estimate & $P$ value \\
\hline $\begin{array}{l}\text { Eating frequency } \ddagger \\
\text { Meal frequency§ } \\
\text { Snack frequencyll }\end{array}$ & $\begin{array}{l}\beta_{1}=0.11 \\
\beta_{1}=0.17 \\
\beta_{1}=0.09\end{array}$ & $\begin{array}{l}<0.001 \\
<0.001 \\
<0.001\end{array}$ & $\begin{array}{l}11.6 \% \text { greater total energy intake } \\
18.5 \% \text { greater total energy intake } \\
9.4 \% \text { greater total energy intake }\end{array}$ & $\begin{array}{l}<0.001 \\
<0.001 \\
<0.001\end{array}$ \\
\hline
\end{tabular}

*Effect estimates from separate multivariable mixed models account for repeat measures and are adjusted for school and free or reduced-price school lunch eligibility.

†Total energy intake log-transformed. Reported $\beta$ coefficients have not been back-transformed. Each additional eating occasion, meal or snack was associated with greater total energy intake reported as a percentage, $\left[\left(\exp \left(\beta_{1}\right)-1\right] \times 100 \%\right.$.

†Eating frequency: number of reported daily eating occasions.

§Meal frequency: number of reported daily meals (breakfast, lunch, dinner/supper).

ISnack frequency: number of reported daily snacks.

Table 4 Associations of eating, meal and snack frequencies with diet quality, as measured by the HEI-2005 (Healthy Eating Index 2005) total score*, in elementary school-age children (9-11 years) and adolescents (12-15 years) who participated in the Daily $D$ diet sub-studyt, greater Boston area, MA, USA, October 2011 to December 2012

\begin{tabular}{|c|c|c|c|c|}
\hline & \multicolumn{2}{|c|}{$\begin{array}{l}\text { Elementary school-age: } \\
9-11 \text { years }(n 92)\end{array}$} & \multicolumn{2}{|c|}{$\begin{array}{c}\text { Adolescents: } \\
\text { 12-15 years ( } n \text { 84) }\end{array}$} \\
\hline & $\beta$ estimate & $P$ value & $\beta$ estimate & $P$ value \\
\hline Eating frequency & $2 \cdot 60$ & 0.003 & -1.40 & 0.16 \\
\hline Meal frequency§ & $3 \cdot 84$ & 0.06 & 5.40 & 0.01 \\
\hline Snack frequencyll & $2 \cdot 31$ & 0.02 & $-2 \cdot 73$ & 0.006 \\
\hline
\end{tabular}

${ }^{*} \mathrm{HEl}-2005$ scores range from 21.9 to 82.3 points (out of a possible 100). †Effect estimates from separate multivariable mixed models account for repeat measures and are adjusted for school, maternal education, free or reduced-price school lunch eligibility and physical activity.

łEating frequency: number of reported daily eating occasions.

§Meal frequency: number of reported daily meals (breakfast, lunch, dinner/ supper).

॥Snack frequency: number of reported daily snacks.

models have been stratified by age category. In elementary school-age participants aged 9-11 years, the relationship between eating frequency and diet quality was statistically significant and positive. After adjusting for maternal education, free or reduced-price lunch eligibility and physical activity, each additional reported daily eating occasion was associated with a 2.60 point increase in total HEI-2005 score $(P=0.003)$. This relationship was not statistically significant in adolescents. In similar but separate models, the relationship between meal frequency and diet quality was positive in both age groups; however, it was statistically significant only in adolescents. Specifically, for each additional reported daily meal, adolescents' total HEI-2005 score increased by 5.40 points $(P=0 \cdot 01)$. The relationship between reported daily snacks and diet quality was statistically significant in both life-stage groups; however, it was positive in elementary school-age participants and inverse in adolescents. It is possible that the positive association in elementary school-age participants is due to higher enrolment in after-school programmes, which must provide snacks that adhere to National School Lunch Program guidelines. Therefore, a $\chi^{2}$ test was performed to look at the difference in location of snacks consumed after school. There were no statistically significant differences between elementary school-age and adolescent participants $(85.5 \%$ snacks at school for 9-11-year-olds $v .82 .9 \%$ in 12-15-year-olds; $P=0.79)$. Finally, we used the eating frequency categories to explore the relationship between eating frequency and the twelve HEI-2005 component scores in both age groups. After adjusting for multiple comparisons, no statistically significant differences were identified (data not shown).

\section{Discussion}

In a population of children at high risk for poor diet and its attendant consequences, eating, meal and snack frequencies were positively associated with total energy intake, whereas the relationships with diet quality differed between meals and snacks and by age category. We hypothesized that eating frequency would be inversely associated with diet quality in light of recent dietary trends in American youth $^{(36)}$. Unexpectedly, in elementary school-age participants, we found that overall eating frequency and snacks positively contributed to diet quality. In adolescents, however, our results suggested that snacks detract from overall diet quality. Specifically, for each additional snack consumed by adolescent participants, total HEI-2005 score statistically significantly decreased by 2.73 points, while each additional meal statistically significantly increased total HEI-2005 score by 5.40 points. In other words, adolescent diet quality decreased with each additional snack and increased with each additional meal.

Why results differ between elementary school-age participants and adolescents is not entirely clear; however, longitudinal trend data suggest that diet quality decreases with the transition from early to middle adolescence, as consumption of fruit and vegetables, $100 \%$ fruit juice, and 
milk and milk products decrease ${ }^{(37,38)}$. It is also possible that because adolescents are generally more autonomous than elementary school-age children, they may make more of their own food choices, particularly at snack time, leading to a decrease in overall diet quality with each additional snack ${ }^{(39)}$. Although we did not collect information regarding family meals, the family meal setting may explain why meals are positively associated with diet quality while snacks are inversely associated with diet quality in adolescents. Family meal frequency has been shown to be positively associated with nutrient intake patterns and inversely associated with sugar-sweetened beverage and fried food intake in both children and adolescents ${ }^{(40)}$.

On average, reported eating frequency and total energy estimates were similar to national estimates ${ }^{(12)}$. Interestingly, research suggests that children who skip meals are more likely to snack; however, in our sample, 'infrequent eaters', the only eating frequency group to consume fewer than the recommended three meals per day, had the fewest number of reported snacks as well ${ }^{(41,42)}$. 'Frequent eaters' had the highest daily total energy intake and reported 2.5 or more snacks per day. These findings support the assertion that older children and adolescents may not compensate for energy intake from snacks at subsequent meals ${ }^{(43)}$. Further, after adjusting for eligibility for free or reduced-priced school lunch, a statistically significant and positive association was observed for eating, meal and snack frequencies with total energy intake. This is not only is consistent with our hypotheses, but it is also supported by the literature. Dietary data from children aged 13-16 years who participated in the Child and Adolescent Trial for Cardiovascular Health show that total energy intake increased linearly with daily eating frequency ${ }^{(42)}$. Other studies have observed a similar relationship, suggesting a positive association between daily meal and snack frequency and total energy intake ${ }^{(44,45)}$.

The present study has noteworthy limitations and strengths. First, our results are valid to the extent that children and adolescents can reliably self-report diet and define meals and snacks. We attempted to address this potential limitation by carrying out the analysis using total eating frequency as well as reported meal and snack frequencies. We recognize that both under- and overreporting is a concern with all self-reported dietary data ${ }^{(46)}$. The aim of our work was to examine how one dietary construct (eating frequency) affects other dietary characteristics (total energy intake and dietary quality, respectively). Considering that all three variables should, in theory, be affected similarly by under- or over-reporting, and because we do not consider any weight-related outcomes in these analyses, we did not identify underor over-reporters in these analyses. Second, we did not collect information on family meals or who purchased and/or prepared meals. Accordingly, we can only hypothesize that these two constructs may have influenced our findings. Third, dietary data were collected for weekdays only, such that the observed associations may only hold during the week while children are at school. Fourth, our findings are cross-sectional in nature such that no conclusions can be made with respect to direction or causality. Finally, generalizability of our findings may be limited beyond racially and socio-economically diverse samples of urban schoolchildren.

Our investigation also has many strengths. We employed registered dietitians to collect repeat, non-consecutive $24 \mathrm{~h}$ recalls using NDSR's multiple-pass method in effort to reduce under-reporting, particularly as it relates to eating occasions. Further, our analytical design, in which we used a mixed model to account for repeat dietary measures, allowed us to account for day-to-day dietary variation. The demographic characteristics of our sample should be considered a strength of this work, given that low-income minority children are at greater risk for poor diet as well as overweight and obesity ${ }^{(47)}$.

\section{Conclusions}

The present study provides evidence that eating frequency, meal frequency and snack frequency are positively associated with total energy intake in a racially and ethnically diverse cohort of low-income children aged 9-15 years. Results suggest that eating frequency, in general, and snacking, in particular, are positively associated with diet quality in elementary school-age participants; however, in adolescents, snack frequency is inversely associated with diet quality while meal frequency is positively associated with diet quality. Given the lack of prospective and experimental studies in this area, further research is needed to explore how eating frequency and diet quality relate to weight gain in both elementary school-age children and adolescents.

\section{Acknowledgements}

Financial support: This study was funded, in part, by the National Institutes of Health (NIH) (grant number NIH R01HL106160), (grant number NIDDK46200 to Boston Nutrition Obesity Research Center); and a National Research Service Award for the NIDDK T32 Research Training Program in Nutrition and Chronic Disease. The $\mathrm{NIH}$ had no role in the design, analysis or writing of this article. Conflict of interest: None. Authorship: E.W.E. developed the research questions; collected, analysed and interpreted the data; and wrote the first draft of the manuscript. P.F.J., G.E.D. and J.S. contributed to the study design and manuscript preparation. A.M. contributed to the study design, data interpretation and manuscript preparation, and provided study oversight. E.W.E. had primary responsibility for final content. All authors have read and approved the final manuscript. Ethics of human subject participation: The work was approved by the Tufts University Institutional Review Board. 


\section{References}

1. Lobstein R, Baur L \& Uauy R (2004) Obesity in children and young people: a crisis in public health. Obes Rev 5, Suppl. 1, 4-104.

2. Guo SS, Wu W, Chumlea WC et al. (2002) Predicting overweight and obesity in adulthood from body mass index values in childhood and adolescence. Am J Clin Nutr 76, 653-658.

3. Birch LL \& Fisher JO (1998) Development of eating behaviors among children and adolescents. Pediatrics 101, Suppl. 2, 539-549.

4. Ludwig DS, Peterson KE \& Gortmaker SL (2001) Relation between consumption of sugar-sweetened drinks and childhood obesity: a prospective, observational analysis. Lancet 357, 505-508.

5. Must A, Barish EE \& Bandini LG (2009) Modifiable risk factors in relation to changes in BMI and fatness: what have we learned from prospective studies of school-aged children? Int J Obes (Lond) 33, 705-715

6. Lise D, Anna F, Manon G et al. (2007) Regular sugarsweetened beverage consumption between meals increases risk of overweight among preschool-aged children. $J$ Am Diet Assoc 107, 924-934.

7. Wang YC, Bleich SN \& Gortmaker SL (2008) Increasing caloric contribution from sugar-sweetened beverages and $100 \%$ fruit juices among US children and adolescents, 1988-2004. Pediatrics 121, e1604-e1614.

8. Ogden CL, Kit BK, Carroll MD et al. (2011) Consumption of Sugar Drinks in the United States, 2005-2008. Hyattsville, MD: National Center for Health Statistics.

9. Rolls BJ, Engell D \& Birch LL (2000) Serving portion size influences 5-year old but not 3-year old children's food intake. J Am Diet Assoc 100, 232-234.

10. Sherry B (2005) Food behaviors and other strategies to prevent and treat pediatric overweight. Int J Obes (Lond) 29, Suppl. 2, S116-S126.

11. Taveras EM, Berkey CS, Rifas-Shiman SL et al. (2005) Association of consumption of fried food away from home with body mass index and diet quality in older children and adolescents. Pediatrics 116, e518-e 524.

12. Popkin BM \& Duffy KJ (2010) Does hunger and satiety drive eating anymore? Increasing eating occasions and decreasing time between eating occasions in the United States. Am J Clin Nutr 91, 1342-1347.

13. Piernas C \& Popkin BM (2011) Food portion patterns and trends among US children and the relationship to total eating occasion size 1977-2006. J Nutr 141, 1159-1164.

14. Piernas C \& Popkin BM (2010) Trends in snacking among US children. Health Aff (Millwood) 29, 398-404.

15. Cole N \& Fox MK (2008) Diet Quality of American School-Age Children by School Lunch Participation Status: Data from the National Health and Nutrition Examination Survey, 1999-2004. Alexandria, VA: US Department of Agriculture, Food and Nutrition Service, Office of Research, Nutrition and Analysis.

16. Kaisari P, Yannakoulia M \& Panagiotakos DB (2013) Eating frequency and overweight and obesity in children and adolescents: a meta-analysis. Pediatrics 131, 958-967.

17. Larson N \& Story M (2013) A review of snacking patterns among children and adolescents: what are the implications of snacking for weight status? Child Obes 9, 104-115.

18. American Dietetic Association (2011) Meal or Eating Frequency and Overweight in Children. http://andevidence library.com/evidence.cfm?evidence_summary_id=21 (accessed September 2011).

19. US Department of Agriculture \& US Department of Health and Human Services (2010) Report of the Dietary Guidelines Advisory Committee of the Dietary Guidelines for Americans. http://www.cnpp.usda.gov/DGAs2010DGACReport.htm (accessed January 2013).
20. Rolls BJ, Engell D \& Birch LL (2000) Serving portion size influences 5-y-old but not 3-y-old children's food intake. $J$ Am Diet Assoc 100, 232-234.

21. Nielsen S, Siega-Riz A \& Popkin BM (2002) Trends in food locations and sources among adolescents and young adults. Prev Med 35, 107-113.

22. Lytle LA, Nichaman MZ, Obarzanek E et al. (1993) Validation of 24-hour recalls assisted by food records in third-grade children. J Am Diet Assoc 93, 1431-1436.

23. Lindquist $\mathrm{CH}$, Cummings T \& Goran MI (2000) Use of taperecorded food records in assessing children's dietary intake. Obes Res 8, 2-11.

24. Cullen KW, Watson K, Himes JH et al. (2004) Evaluation of quality control procedures for 24-h dietary recalls: results from the Girls Health Enrichment Multisite Studies. Prev Med 38, Suppl., S14-S23.

25. Baxter SD, Thompson WO, Litaker MS et al. (2003) Accuracy of fourth-graders' dietary recalls of school breakfast and school lunch validated with observations: in-person versus telephone interviews. J Nutr Educ Behav 35 , 124-134.

26. Hart CN, Raynor HA, Osterholt KM et al. (2011) Eating and activity habits of overweight children on weekdays and weekends. Int J Pediatr Obes 6, 467-472.

27. Thompson OM, Ballew C, Resnicow K et al. (2006) Dietary pattern as a predictor of change in BMI Z-score among girls. Int J Pediatr Obes 30, 176-182.

28. Guenther P, Reedy J \& Krebs-Smith S (2008) Development of the Healthy Eating Index-2005. J Am Diet Assoc 108, 1896-1901.

29. Fox MK, Clark MA, Condon E et al. (2010) Diet Quality of School-Age Children in the US and Association with Participation in the School Meal Programs. Cambridge, MA: Mathematica Policy Research, Inc.

30. Institue of Medicine (2005) Dietary Reference Intakes for Energy, Carbohydrate, Fiber, Fat, Fatty Acids, Cholesterol, Protein, and Amino Acids. Washington, DC: National Academies Press; available at http://www.nal.usda.gov/fnic/ DRI/DRI_Energy/energy_full_report.pdf

31. US Department of Agriculture (2010) Healthy Eating Index2005 Development and Evaluation Technical Report Support Files. http://www.cnpp.usda.gov/HealthyEatingIndex2005report.htm (accessed September 2011).

32. Miller PE, Mitchell D, Harala P et al. (2011) Development and evaluation of a method for calculating the Healthy Eating Index-2005 using the Nutrition Data System for Research. Public Health Nutr 14, 306-313.

33. Drahovzal D, Bennett T, Campagne P et al. (2003) Comparison of the Block Child Activity Screener with an Objective Measure of Physical Activity. Quebec: International Society of Behavioral Nutrition and Physical Activity.

34. US Department of Health and Human Services (2008) Physical Activity Guidelines for Americans: Appendix 1 Translating scientific evidence about total amount and intensity of physical activity into guidelines. http://www. health.gov/paguidelines/guidelines/appendix1.aspx (accessed June 2012).

35. Rothman K, Greenland S \& Lash T (2008) Modern Epidemiology, 3rd ed. Philadelphia, PA: Lippincott Williams \& Wilkins.

36. Reedy J, Krebs-Smith SM (2010) Dietary sources of energy, solid fats, and added sugars among children and adolescents in the United States. J Am Diet Assoc 110, 1477-1484.

37. Nelson MC, Neumark-Sztainer D, Hannan PJ et al. (2009) Five-year longitudinal and secular shifts in adolescent beverage intake: findings from Project EAT (Eating Among Teens)-II. J Am Diet Assoc 109, 308-312.

38. Larson N, Neumark-Sztainer D, Hannan PJ et al. (2007) Trends in adolescent fruit and vegetable consumption, 1999-2004. Am J Prev Med 32, 147-150. 
39. Neumark-Sztainer D, Story M, Perry C et al. (1999) Factors influencing food choices of adolescents: findings from focus-group discussions with adolescents. J Am Diet Assoc 99, 929-937.

40. Gilman M, Rifas-Shiman S, Frazier L et al. (2000) Family dinner and diet quality among older children and adolescents. Arch Fam Med 9, 235-240.

41. Savige G, Macfarlane A, Ball K et al. (2007) Snacking behaviors of adolescents and their association with skipping meals. Int J Behav Nutr Phys Act 4, 36.

42. Dwyer JT, Evans M, Stone EJ et al. (2001) Adolescents' eating patterns influence their nutrient intakes. $\mathrm{Am}$ Diet Assoc 101, 798-802.

43. Marmonier C, Chapelot D \& Louis-Sylvestre J (2000) Effects of macronutrient content and energy density of snacks consumed in a satiety state on the onset of the next meal. Appetite 34, 161-168.

44. Toschke A, Kuchenhoff H, Koletzko B et al. (2005) Meal frequency and childhood obesity. Obes Res 13, 1932-1938.

45. Macdiarmid J, Loe J, Craig LCA et al. (2009) Meal and snacking patterns of school-aged children in Scotland. Eur J Clin Nutr 63, 1297-1304.

46. Hare M, Sherrill-Mittleman D, Klesges R et al. (2012) Energy underreporting in African-American girls: a longitudinal analysis. Child Obes $\mathbf{8}, 551-560$.

47. Ogden CL, Carroll MD, Kit BK et al. (2012) Prevalence of obesity and trends in body mass index among US children and adolescents, 1999-2010. J Am Med Assoc 307, 483-490. 